\title{
Illness prevalence rate in Tibet, China: data from the 2018 National Health Service Survey
}

Rendan Deng ${ }^{1}$, Labasangzhu ${ }^{2 *}$, Zhaxideji ${ }^{2^{*}}$, Guihua Wang ${ }^{1}$, Peiwei Hong ${ }^{1}$, Jiaqi Li ${ }^{1}$, Qiwen Li ${ }^{1}$, Yang Wan ${ }^{{ }^{*}}$ and Hai Xiong ${ }^{1,2^{*}}$

\begin{abstract}
Background: Tibet is located in the high-altitude area of Southwest China, where the health level is influenced by specific factors such as the natural environment and living habits. However, there has been little research that has focused on Tibetan health conditions. The two-week prevalence rate is an important indicator of the health level of residents. The purpose of this study was to understand the health status of the residents and the health service needs in Tibet.

Methods: The two-week prevalence rate was calculated using data from a population of 10,493 individuals aged 15 and above that was obtained from the 2018 Sixth National Health Service Survey of Tibet. We initially analysed the types and associated factors of two-week illnesses in Tibetan. The influencing factors for the two-week prevalence rate in Tibet were determined by multivariate logistic regression analysis. Subsequently, we assessed the severity of two-week illnesses by calculating the average days of the duration of the disease, the days of being bedridden and the days of being off work.

Results: The two-week illness prevalence rate was $20.1 \%$ in Tibet. Digestive system diseases were frequent, and hypertension was the most common disease. According to the multivariate logistic regression analysis, the two-week prevalence rate was associated with gender, age, residence, marital status, and employment status. In addition, the severity of two-week illnesses differed among the residents.

Conclusion: This study identified that health service needs have increased in Tibet and that the health status of the local residents needs to be improved. Moreover, hypertension has become a major health hazard for the residents and should be considered in the utilization of health services.
\end{abstract}

Keywords: Tibetan, Two-week prevalence rate, Factors

\section{Background}

The Tibet Autonomous Region is located in Southwestern China. It covers an area of 1.23 million square kilometres and has a population of approximately 3.3 million. The natural environment and living habits of Tibetans are significantly different from those in other

\footnotetext{
*Correspondence: Ihasam@qq.com; tumczhade@163.com; Wanyang2014@scu.edu.cn; xhxysq@126.com

${ }^{2}$ Medical College of Tibet University, Lhasa 850000, China ${ }^{1}$ West China School of Public Health and West China Fourth Hospital, Sichuan University, Chengdu 610041, China
}

parts of China, as the altitude is over $4000 \mathrm{~m}$ [1]. The local residents mainly obtain nutrients and energy from traditional foods such as Zanba, Tibetan salt cream tea, and Tibetan milk tea $[2,3]$. Many countries, such as the United States, Ethiopia and Kenya, attach importance to local health services to establish effective health service systems [4-6]. In addition, China has been developing a primary health-care system [7].

Previous studies have shown that morbidity is the dominant predictor of health service utilization. In addition, the two-week prevalence rate is an important

(c) The Author(s). 2020 Open Access This article is licensed under a Creative Commons Attribution 4.0 International License, which permits use, sharing, adaptation, distribution and reproduction in any medium or format, as long as you give appropriate credit to the original author(s) and the source, provide a link to the Creative Commons licence, and indicate if changes were made. The images or other third party material in this article are included in the article's Creative Commons licence, unless indicated otherwise in a credit line to the material. If material is not included in the article's Creative Commons licence and your intended use is not permitted by statutory regulation or exceeds the permitted use, you will need to obtain permission directly from the copyright holder. To view a copy of this licence, visit http://creativecommons.org/licenses/by/4.0/. The Creative Commons Public Domain Dedication waiver (http://creativecommons.org/publicdomain/zero/1.0/) applies to the data made available in this article, unless otherwise stated in a credit line to the data. 
index for evaluating health service needs, which can reflect the health level and social health status of the population [8]. In China, there are huge differences in the two-week prevalence among different regions $[9,10]$. The Fourth National Health Service Survey of China showed that Chengguan District in Lahsa, Tibet has a minimal two-week prevalence rate of $5.2 \%$, while the Dongcheng District in Beijing has a maximal two-week prevalence rate of $53.2 \%$ [11]. The Fifth National Health Service Survey of China showed that the two-week prevalence rate was $32.1 \%$ in West China, which is lower than the $26.2 \%$ prevalence rate found in East China [12]. The health status of the local residents in Tibet has seldom been reported. In this study, the two-week prevalence rate and factors based on data from the Sixth National Health Service Survey of Tibet, China, which was completed in 2018, are reported.

\section{Methods}

\section{Data source}

Data were obtained from the 2018 Sixth National Health Service Survey of Tibet, China. The Tibet Autonomous Region has jurisdiction over seven prefecture-level cities, consisting of 74 counties. Therefore, according to the level of economic development, geographical location, population distribution and other factors, 13,102 residents from 3060 households were finally included in this survey, according to the multistage stratified cluster random sampling method.

By performing a face-to-face survey using an electronic tablet, the investigator inquired about all the members of each household one by one, filled in the related electronic questionnaires offline [13], and then uploaded the survey data online after the survey instructors examined the responses for each person. Because this study was a national survey project and was organized by the relevant departments of the government, the selected residents actively cooperated with the survey. Therefore, there was no refusal to answer. However, there were 525 cases with missing data. Subjects were eligible to participate in the current study if they (1) were $\geq 15$ years old and (2) were permanent residents of the sample households. A total of 10,493 valid cases were finally included. In principle, all the contents of the survey should be answered by the respondents. However, people who were not at home or those who were unable to respond during the survey period were replaced by those who were familiar with their situation.

This study was part of the Sixth National Health Service Survey of China, which was approved by the National Health and Family Planning Commission of the People's Republic of China and by the Health and Family Planning Commission of the Tibet Autonomous Region.
Oral consent was obtained before the eligible residents took the survey.

\section{The definitions of the outcome variables}

The illness types are listed in Additional file 1. A twoweek illness was defined as the respondents having undergone any of the following three circumstances less than 2 weeks before being interviewed: 1) visiting a doctor; 2) receiving medical treatment for the illness or injury; or 3) being bedridden or off work due to illness (including obvious abnormal depression and loss of appetite in elderly people) for at least 1 day.

The two-week prevalence rate was calculated by the following formula: Two-week prevalence rate $=($ Number of respondents with two-week illness) *100\% / (The total number of respondents).

Gender, age, residence, education, economic level, marital status, and employment status were selected as covariates to examine their impacts on the two-week prevalence rate. We divided age into 4 groups: 15-29 years old, 30-44 years old, 45-59 years old, and 60years old. Residence was divided into 2 groups: rural and urban. Education was divided into 5 groups: illiterate, primary school, junior middle school, high school, and university and above. Economic level was grouped according to the quartile of annual income per capita: low, medium and high, with the grouping cut-offs being 3333 yuan, 6000 yuan, and 12,000 yuan, respectively. Marital status was divided into married, unmarried, widowed, divorced and other. Employment status was divided into employed, retired, laid-off, unemployed, and student. In addition, we measured the severity of the two-week illness by calculating the average duration of the disease in days, the number of days of being bedridden and the number of days of being off work.

\section{Statistical analysis}

A chi-square test was performed to examine the significance of the differences in the two-week prevalence rates according to the demographic variables. Whether an individual was sick within the previous 2 weeks was used as a dichotomous variable. A multivariate logistic regression analysis was further conducted, and the variables with statistical significance were included in the analysis. With respect to the number of subjects suffering from chronic diseases, a multivariate regression analysis was performed to adjust for confounding factors, including gender, age, residence, economic level, education level, economic level, marital status, and employment status. In addition, a one-way analysis of variance was used to determine the severity of the two-week prevalence rate in different groups. The data analysis was completed using Statistical Package for Social Science (SPSS) 
version 20.0 statistical software (IBM, Armonk, NY, USA) and $p<0.05$ was set as the test level.

\section{Results}

Overall, 10,493 residents aged 15 and above were included in this study. The proportion of women (53.1\%) was higher than that of men. The average age of the subjects in this study was $44.1 \pm 15.7$ years old. Tibetans accounted for the highest proportion (97.0\%) among the ethnic groups in Tibet. The two-week prevalence rate was $20.1 \%$ in Tibet in 2018 (see Table 1).

Digestive diseases, cardiovascular diseases, musculoskeletal diseases, respiratory diseases, and urogenital diseases accounted for the top five diseases by body system, with prevalences of $27.8,20.5,16.5,11.6$ and $4.4 \%$, respectively. Moreover, in terms of the composition of diseases, the top five chronic diseases were hypertension (14.4\%), rheumatoid arthritis (8.0\%), cholelithiasis (6.3\%), chronic gastritis (5.5\%), and diabetes mellitus (0.9\%) (data not shown).

Among the patients, the two-week prevalence rate of females was significantly higher than that of males. The two-week prevalence rate was positively associated with age and economic level, and it was inversely associated with education. Urban residents had a higher two-week prevalence rate than that of rural residents $(27.7 \%$ vs. $18.0 \%)$. The two-week prevalence rate of widows was the highest, reaching $35.8 \%$. Among people with different employment statuses, the two-week prevalence rate of the unemployed population was the highest, reaching $41.7 \%$, followed by that of the retired population at $37.2 \%$. The characteristics of the survey participants are presented in Table 1.

To further study the influencing factors of the twoweek prevalence rate, a regression analysis was performed. A chi-square test found that the two-week

Table 1 Sociodemographic characteristics and illness prevalence rates among residents over 15 years old from Tibet in 2018

\begin{tabular}{|c|c|c|c|c|c|c|}
\hline \multirow[t]{2}{*}{ Characteristics } & & \multirow[t]{2}{*}{ Number } & \multirow{2}{*}{$\begin{array}{l}\text { Proportion } \\
\text { (\%) }\end{array}$} & \multicolumn{2}{|l|}{ Two-week Illness } & \multirow{2}{*}{$\begin{array}{l}p \\
\text { value }\end{array}$} \\
\hline & & & & Number of illnesses & Prevalence rate (\%) & \\
\hline & Total & 10,493 & 100.0 & 2104 & 20.1 & \\
\hline \multirow[t]{2}{*}{ Gender } & Male & 4921 & 46.9 & 795 & 16.2 & $<0.001$ \\
\hline & Female & 5572 & 53.1 & 1309 & 23.5 & \\
\hline \multirow[t]{4}{*}{ Age } & $15-29$ & 2086 & 19.9 & 176 & 8.4 & $<0.001$ \\
\hline & $30-44$ & 3412 & 32.5 & 511 & 15.0 & \\
\hline & $45-59$ & 3245 & 30.9 & 865 & 26.6 & \\
\hline & $60-$ & 1750 & 16.7 & 553 & 31.6 & \\
\hline \multirow[t]{2}{*}{ Residence } & Urban & 2186 & 20.8 & 606 & 27.7 & $<0.001$ \\
\hline & Rural & 8307 & 79.1 & 1498 & 18.0 & \\
\hline \multirow[t]{5}{*}{ Education } & Illiterate & 5037 & 48.0 & 1181 & 23.4 & $<0.001$ \\
\hline & Primary school & 3496 & 33.3 & 668 & 19.1 & \\
\hline & Junior middle school & 1217 & 11.6 & 156 & 12.8 & \\
\hline & High school & 603 & 5.7 & 90 & 14.9 & \\
\hline & University and above & 140 & 1.3 & 10 & 7.1 & \\
\hline \multirow[t]{3}{*}{ Economic level } & Low & 2524 & 24.1 & 457 & 18.1 & 0.008 \\
\hline & Medium & 5311 & 50.6 & 1075 & 20.2 & \\
\hline & High & 2658 & 25.3 & 572 & 21.5 & \\
\hline \multirow[t]{5}{*}{ Marital status } & Married & 7950 & 75.7 & 1624 & 20.4 & $<0.001$ \\
\hline & Unmarried & 1567 & 15.0 & 148 & 9.4 & \\
\hline & Widowed & 719 & 6.9 & 258 & 35.8 & \\
\hline & Divorced & 186 & 1.8 & 59 & 31.6 & \\
\hline & Others & 71 & 0.7 & 16 & 22.5 & \\
\hline \multirow[t]{5}{*}{ Employment status } & Employed & 8232 & 78.4 & 1483 & 18.0 & $<0.001$ \\
\hline & Retired & 207 & 2.0 & 77 & 37.2 & \\
\hline & Laid-off & 168 & 1.6 & 70 & 41.7 & \\
\hline & Unemployed & 1601 & 15.3 & 467 & 29.1 & \\
\hline & Student & 285 & 2.7 & 8 & 2.8 & \\
\hline
\end{tabular}


prevalence rate was associated with gender, age, residence, economic level, marital status and employment status. In an unadjusted regression analysis, the participants who were women, older, and urban residents and those who had a higher economic level and poor marital and employment statuses had a higher odds ratio (OR) for morbidity compared with the other groups. Other than for economic level, the effect size remained significant after adjusting for other factors (see Table 2).

In addition, the duration of the two-week illness was positively associated with age. There were differences according to urban-rural residence, education, annual income per capita, marital status, and employment status. The duration of being bedridden for the two-week illness also differed by age, residence, education, and employment status. Rural residents were off work longer than urban residents. (see Table 3).

\section{Discussion}

Based on the 2018 Sixth National Health Service Survey in the Tibet Autonomous Region, the two-week prevalence rate and its influencing factors were analysed. This study showed that the two-week prevalence rate of the residents aged 15 years and older in Tibet was $20.1 \%$ in 2018, which was higher than the rate from the Fifth National Health Service Survey in Tibet (10.6\%) [12]; this finding indicates that the health service needs in Tibet significantly increased between the times of the two surveys. The two-week prevalence rate is an important index for evaluating the utilization of health services. Our results showed that the two-week prevalence rate in Tibet was influenced by multiple factors. On the one hand, health insurance coverage has increased from 29.7\% in 2003 to $97.0 \%$ in 2015 in China. Health insurance coverage has reached approximately $95 \%$ in Tibet $[14,15]$. Additionally, both the education level and

Table 2 The influencing factors of the two-week prevalence rate according to the univariate and multivariate analysis of individuals from Tibet in 2018

\begin{tabular}{|c|c|c|c|c|c|c|}
\hline Influence factor & & Crude OR & $95 \% \mathrm{Cl}$ & Adjusted OR & $95 \% \mathrm{Cl}$ & ${ }^{*} p$ value \\
\hline \multirow[t]{2}{*}{ Gender } & Female & 1.000 & & 1.000 & & \\
\hline & Male & 0.627 & $(0.569,0.692)$ & 0.691 & $(0.622,0.767)$ & $<0.001$ \\
\hline \multirow[t]{4}{*}{ Age } & $15-29$ & 1.000 & & 1.000 & & \\
\hline & $30-44$ & 1.912 & $(1.595,2.290)$ & 1.464 & $(1.201,1.784)$ & $<0.001$ \\
\hline & $45-59$ & 3.944 & $(3.318,4.689)$ & 2.804 & $(2.304,3.413)$ & $<0.001$ \\
\hline & $60-$ & 5.000 & $(4.158,6.013)$ & 2.968 & $(2.367,3.722)$ & $<0.001$ \\
\hline \multirow[t]{2}{*}{ Residence } & Urban & 1.000 & & 1.000 & & \\
\hline & Rural & 0.574 & $(0.514,0.640)$ & 0.610 & $(0.541,0.689)$ & $<0.001$ \\
\hline \multirow[t]{5}{*}{ Education } & Illiterate & 1.000 & & 1.000 & & \\
\hline & Primary school & 0.772 & $(0.694,0.859)$ & 0.921 & $(0.822,1.032)$ & 0.155 \\
\hline & Junior middle school & 0.481 & $(0.401,0.576)$ & 0.876 & $(0.717,1.072)$ & 0.199 \\
\hline & High school & 0.573 & $(0.454,0.724)$ & 0.974 & $(0.741,1.279)$ & 0.849 \\
\hline & University and above & 0.251 & $(0.132,0.480)$ & 0.568 & $(0.288,1.120)$ & 0.102 \\
\hline \multirow[t]{3}{*}{ Economic level } & Low & 1.000 & & 1.000 & & \\
\hline & Medium & 1.148 & $(1.017,1.296)$ & 1.134 & $(1.000,1.287)$ & 0.051 \\
\hline & High & 1.240 & $(1.081,1.423)$ & 1.106 & $(0.953,1.283)$ & 0.185 \\
\hline \multirow[t]{5}{*}{ Marital status } & Married & 1.000 & & 1.000 & & \\
\hline & Unmarried & 0.407 & $(0.340,0.486)$ & 0.684 & $(0.562,0.832)$ & $<0.001$ \\
\hline & Widow & 2.182 & $(1.856,2.565)$ & 1.279 & $(1.070,1.529)$ & 0.007 \\
\hline & Divorce & 1.781 & $(1.324,2.478)$ & 1.644 & $(1.187,2.277)$ & 0.003 \\
\hline & Others & 1.134 & $(0.648,1.984)$ & 1.023 & $(0.575,1.819)$ & 0.940 \\
\hline \multirow[t]{5}{*}{ Employment status } & Employed & 1.000 & & 1.000 & & \\
\hline & Retired & 2.696 & $(2.022,3.593)$ & 1.295 & $(0.945,1.776)$ & 0.108 \\
\hline & Laid-off & 3.251 & $(2.380,4.440)$ & 2.360 & $(1.695,3.287)$ & $<0.001$ \\
\hline & Unemployed & 1.868 & $(1.655,2.110)$ & 1.238 & $(1.075,1.424)$ & 0.003 \\
\hline & Student & 0.131 & $(0.065,0.266)$ & 0.334 & $(0.159,0.701)$ & 0.004 \\
\hline
\end{tabular}

$\&: p$ value adjusted by multivariate logistic regression analysis 
Table 3 The severity of two-week illnesses in Tibet in 2018

\begin{tabular}{|c|c|c|c|c|c|c|c|}
\hline \multicolumn{2}{|l|}{ Characteristics } & \multicolumn{2}{|c|}{${ }^{a}$ Duration } & \multicolumn{2}{|c|}{${ }^{a}$ Being bedridden } & \multicolumn{2}{|c|}{ a Being off work } \\
\hline & & Mean & $95 \% \mathrm{Cl}$ & Mean & $95 \% \mathrm{Cl}$ & Mean & $95 \% \mathrm{Cl}$ \\
\hline \multirow[t]{2}{*}{ Gender } & Male & 8.47 & $(8.13,8.82)$ & 4.53 & $(3.51,5.54)$ & 1.64 & $(0.18,3.10)$ \\
\hline & Female & 8.54 & $(8.27,8.81)$ & 4.43 & $(3.78,5.07)$ & 2.29 & $(0.03,4.56)$ \\
\hline \multirow[t]{4}{*}{ *キ Age } & $15-29$ & 7.41 & $(6.72,8.10)$ & 3.04 & $(1.54,4.55)$ & 1.67 & $(0.21,5.46)$ \\
\hline & $30-44$ & 7.77 & $(7.36,8.19)$ & 3.40 & $(2.56,4.25)$ & 2.20 & $(1.77,6.17)$ \\
\hline & $45-59$ & 8.52 & $(8.19,8.86)$ & 4.05 & $(3.19,4.91)$ & 1.94 & $(0.08,3.80)$ \\
\hline & $60-$ & 9.54 & $(9.14,9.95)$ & 6.32 & $(5.14,7.50)$ & 2.17 & $(0.34,7.74)$ \\
\hline \multirow[t]{2}{*}{ *\#キ Residence } & Urban & 8.18 & $(7.77,8.59)$ & 4.20 & $(3.24,5.16)$ & 1.40 & $(0.12,2.92)$ \\
\hline & Rural & 8.65 & $(8.41,8.89)$ & 4.59 & $(3.93,5.25)$ & 2.29 & $(0.38,4.19)$ \\
\hline \multirow[t]{5}{*}{ *\# Education } & Illiterate & 9.05 & $(8.78,9.33)$ & 5.35 & $(4.55,6.15)$ & 2.58 & $(0.68,5.85)$ \\
\hline & Primary school & 7.89 & $(7.51,8.26)$ & 3.55 & $(2.74,4.36)$ & 1.53 & $(0.09,2.98)$ \\
\hline & Junior middle school & 7.54 & $(6.76,8.32)$ & 2.36 & $(0.76,3.96)$ & 2.00 & $(0.70,3.30)$ \\
\hline & High school & 8.00 & $(6.89,9.11)$ & 4.31 & $(1.95,6.67)$ & / & / \\
\hline & University and above & 7.00 & $(2.93,11.07)$ & / & / & / & / \\
\hline \multirow[t]{3}{*}{ *Economic level } & Low & 8.45 & $(8.01,8.89)$ & 3.93 & $(2.91,4.94)$ & 4.62 & $(3.36,5.88)$ \\
\hline & Medium & 8.67 & $(8.38,8.96)$ & 4.92 & $(4.09,5.75)$ & 2.83 & $(2.07,3.60)$ \\
\hline & High & 8.28 & $(7.86,8.70)$ & 4.13 & $(3.12,5.14)$ & 2.38 & $(1.43,3.33)$ \\
\hline \multirow[t]{5}{*}{ *Marital status } & Married & 8.33 & $(8.09,8.56)$ & 3.98 & $(3.39,4.56)$ & 1.84 & $(0.48,3.20)$ \\
\hline & Unmarried & 9.10 & $(8.29,9.91)$ & 4.77 & $(2.61,6.94)$ & 1.00 & $(0.12,13.71)$ \\
\hline & Widow & 9.31 & $(8.69,9.93)$ & 6.54 & $(4.70,8.38)$ & 6.50 & $(0.76,8.90)$ \\
\hline & Divorce & 8.10 & $(6.82,9.39)$ & 4.11 & $(0.54,7.68)$ & / & / \\
\hline & Others & 10.94 & $(8.66,13.22)$ & 6.00 & $(1.93,10.07)$ & / & / \\
\hline \multirow[t]{5}{*}{ *キ Employment status } & Employed & 8.11 & $(7.86,8.36)$ & 3.61 & $(3.02,2.00)$ & 2.00 & $(0.67,3.33)$ \\
\hline & Retired & 9.74 & $(8.56,10.92)$ & 3.33 & $(0.13,6.79)$ & / & / \\
\hline & Laid-off & 10.00 & $(8.87,11.13)$ & 6.53 & $(3.25,9.81)$ & / & / \\
\hline & Unemployed & 9.40 & $(8.95,9.85)$ & 6.17 & $(5.03,7.32)$ & / & / \\
\hline & Student & 7.63 & $(3.29,11.96)$ & / & / & / & / \\
\hline
\end{tabular}

\footnotetext{
${ }^{a}$ : measured in days

*: There were differences in duration among the different groups, $p<0.05$

\#: There were differences in being bedridden among the different groups, $p<0.05$

\#: There were differences in the duration of being off work among the different groups, $p<0.05$

/: There were no subjects satisfying the grouping condition
}

health awareness of Tibetans have improved. Therefore, more residents choose to actively seek medical treatment.

Among the disease systems, the digestive system had the largest proportion of diseases; however, cardiovascular system diseases were prioritized according to the national survey results [12] and may be related to food habits (such as special Tibetan dietary habits). The traditional Tibetan diet is almost $60 \%$ protein and high in fat [2]. In the traditional Tibetan dietary model, protein and fat provide approximately $60 \%$ of the daily energy intake, making food difficult to digest and be absorbed by the human body. Moreover, hypertension has been reported as the most common chronic disease in Tibet, which may be related to the diet and awareness of Tibetans $[16,17]$. A high-salt diet and an insufficient awareness of hypertension lead to an increase in medical treatment $[18,19]$. Nevertheless, in this study, the self-reported prevalence of hypertension was $14.4 \%$ among the patients, which was lower than the national level $(23.2 \%)$ [20]. This outcome indicates the inadequate utilization of health services to a certain extent in Tibet.

In this study, we found that the two-week prevalence rate among females was higher than that among males. The reason for this outcome may be that women have special physiological periods, namely menstruation, pregnancy, childbirth, puerperium and breastfeeding, which result in special needs $[21,22]$. Compared with men, women have lower immunity and more delicate emotions, making them more likely to pay attention to their own health needs. According to the findings of Anna Ruggieri [23], it appears that differences in 
hormonal, genetic and environmental factors between males and females may affect immune responses. In addition, females may more actively utilize health services because they pay more attention to their health than do males.

With increasing age, the two-week prevalence rate showed a linearly increasing trend, which is supported by studies [24] that have shown that various kinds of physical diseases gradually increase with increasing age. For most older people, physical and social activities show a downward trend, which weakens the immunity of the body. In addition, most women over 60 are menopausal, and their health might thus be affected by hormone levels [25]. Older people who are more sensitive to illness may promote their use of medical services.

In addition, we found that the two-week prevalence rate may be related to residence, marital status, and employment status. We identified factors that differed between rural and urban residences of two-week prevalence rates. The risk of the two-week disease of urban residents was higher than that of rural residents, which may be because the education level and health awareness of urban residents were higher than those of farmers and herdsmen [26, 27]. Moreover, the distance between residential areas and clinical areas in agricultural and pastoral areas was relatively farther than that in urban areas, which might affect the accessibility of medical treatment for farmers and herdsmen to a certain extent. Therefore, the reported prevalence rate was low, which was similar to the results from Tian, D [28]. Compared with married people, the two-week prevalence of widowed and divorced people was higher. The reason may be that the previous way of life or environment of people who experienced widowhood or divorce, to a certain extent, would be changed. On the other hand, widowed patients were also more likely to be older, and the results were consistent with age. Therefore, widowed patients may experience a certain negative psychological impact on their health. A happy marriage and good family care are conducive to reducing the occurrence of illness and accelerating one's recovery from illness. In different employment situations, unemployment and being laid off were risk factors for a two-week illness, which is similar to the results from the Fifth National Health Service Survey [12]. To a certain extent, an irregular daily life and realistic pressure are negative factors of illness [29]. As a special social group, school students are at an early life stage and have relatively low life pressure and regular living habits, and most of them are energetic because of their youth and have good physical immunity; thus, their possibility of experiencing a two-week illness was low.

There were several limitations in this study. First, this cross-sectional study was insufficient for making causal inferences. Therefore, we could only provide the possible influencing factors for the two-week illness rate. Second, because the respondent's illness rate was self-reported, the actual two-week illness rate may be underestimated due to recall bias and a low diagnosis rate. Third, due to the lack of longitudinal data, we were unable to examine changes in the two-week prevalence rate.

\section{Conclusion}

In conclusion, the two-week prevalence rate in 2018 was significantly higher than that from the Fifth National Health Survey in Tibet, indicating that the needs for health care have increased greatly and that the health level needs improvement. The two-week prevalence rate of Tibetans was generally associated with gender, age, residence, marital status, and employment status. In addition, the severity of the two-week prevalence rate was different among groups based on age, residence, education, marital status, and employment status. Therefore, many efforts should be made by the central and local governments of China to improve the health of Tibetans because of the severity of the disparity. This study may provide a basis for formulating health service policies about residents with different characteristics for the government.

\section{Supplementary information}

Supplementary information accompanies this paper at https://doi.org/10. 1186/s12889-020-08960-7.

Additional file 1. The classifications of diseases in the Sixth National

Health Service Survey, 2018.

\section{Abbreviations}

$\mathrm{Cl}$ : Confidence interval; OR: Odds ratio

\section{Acknowledgements}

We would like to express our gratitude to all those who helped us during the writing of this research. First and foremost, we would like to show our deepest gratitude to Professor Peiyuan Qiu, who has offered us valuable suggestions at the department of English. We are also indebted to all the other teachers in translation studies for their direct and indirect help to us.

\section{Authors' contributions}

$\mathrm{RD}$ led the analysis, wrote the manuscript and edited the final manuscript for publication. L acquired and interpreted the data. Z, GW and PH assisted with data analysis and interpretation. JL and QL provided critical modification suggestions on the manuscript. YW provided statistical advice and corrected the manuscript. L, Z, YW and HX were responsible for the supervision of the project. The the authors have read and approved the final manuscript.

\section{Funding}

This work was supported by the Sixth National Health Service Survey in Tibet (NO.18080027), Cultivation Fund Project of Tibet university (ZDTSJH18-09), Natural Science Foundation of Tibet autonomous region (2016ZR-TU-06) and Genetic resources of the normal population and diseases on the QinghaiTibet Plateau (NO.00060464). The listed grant funders played no role in any step of this study. 


\section{Availability of data and materials}

The datasets that support the findings of this study are available from Medical College of Tibet University but are restricted to the availability of these data, which were used under license for the current study, and so are not publicly available. Data are however available from the authors upon reasonable request and with permission of Medical College of Tibet University.

\section{Ethics approval and consent to participate}

The National Health and Family Planning Commission of the People's Republic of China and the Health and Family Planning Commission of Tibet autonomous region approved the study. Local health research projects which meet ethical requirements can be implemented with the approval of these two departments. The Medical Ethics Expert Committee of the National Health and Family Planning Commission of the People's Republic of China is a legitimate ethical review institution in China. It conducts research on major ethical issues in biomedical research involving human beings, directs and supervises the work of provincial medical ethics expert committees, and jointly inspects and evaluates the work of institutional ethics committees

Because of the subjects of this study were Tibetan residents with a low educational level and a large sample size, the investigators use verbal informed consents to inform the respondents of the purpose of the survey in accordance with the prepared electronic version of the informed consent. Verbal consent was approved by the the National Health and Family Planning Commission of the People's Republic of China and by the Health and Family Planning Commission of the Tibet Autonomous Region. Verbal consents were obtained before the survey from the eligible residents. Consent was obtained from a parent or guardian on behalf of the participants under the age of 16 . And all the participants are Chinese, and they resided in China.

\section{Consent for publication}

Not applicable.

\section{Competing interests}

The authors declare that they have no competing interests.

\section{Received: 2 September 2019 Accepted: 19 May 2020}

Published online: 18 June 2020

\section{References}

1. Shen L, Zhang X, Dawawuzhu, et al. Pain Clinic in Tibet, China: a singlecenter retrospective study. Pain Res Manag. 2019;2019:9161906. https://doi. org/10.1155/2019/9161906.

2. Wang Z, Dang $S$, Xing Y, et al. Dietary patterns and their associations with energy, nutrient intake and socioeconomic factors in rural lactating mothers in Tibet. Asia Pac J Clin Nutr. 2017;26(3):450-6. https://doi.org/10.6133/apjcn. 012016.13.

3. Sánchez-Villegas A, Delgado-Rodríguez M, Martínez-González MA, et al. Gender, age, socio-demographic and lifestyle factors associated with major dietary patterns in the Spanish project SUN (Seguimiento Universidad de Navarra). Eur J Clin Nutr. 2003;57(2):285-92. https://doi.org/10.1038/sj.ejcn. 1601528.

4. Blackwell DL, Lucas JW, Clarke TC. Summary health statistics for U.S. adults: national health interview survey, 2012. Vital Health Stat 10. 2014;(260):1-161. https:/pubmed.ncbi.nIm.nih.gov/24819891/. PMID: 24819891.

5. Girma F, Jira C, Girma B. Health services utilization and associated factors in Jimma zone, south West Ethiopia. Ethiop J Health Sci. 2011; 21(Suppl 1):85-94.

6. Ngugi AK, Agoi F, Mahoney MR, et al. Utilization of health services in a resource-limited rural area in Kenya: prevalence and associated householdlevel factors. PLoS One. 2017;12(2):e0172728. Published 2017 Feb 27. https:// doi.org/10.1371/journal.pone.0172728.

7. Tanahashi T. Health service coverage and its evaluation. Bull World Health Organ. 1978:56(2):295-303.

8. Li YN, Nong DX, Wei B, et al. The impact of predisposing, enabling, and need factors in utilization of health services among rural residents in Guangxi, China. BMC Health Serv Res. 2016;16(1):592.

9. Yang G, Wang Y, Zeng Y, et al. Rapid health transition in China, 1990-2010: findings from the global burden of disease study 2010. Lancet. 2013; 381(9882):1987-2015. https://doi.org/10.1016/50140-6736(13)61097-1.
10. Jiang $Y$, Zheng $H$, Zhao $T$. Socioeconomic status and morbidity rate inequality in China: based on NHSS and CHARLS data. Int J Environ Res Public Health. 2019;16(2):215. Published 2019 Jan 14. https://doi.org/10. 3390/ijerph16020215.

11. Center for Health Statistics and Information, the Ministry of Health of China. Summary of the report on the 3rd national health services survey analysis. Chinese Hospitals. 2005;9(1):3-11.

12. National Health and Family Planning Commission of China, scheme of fifth National Health Se- rvice survey of China (in Chinese). Available at: http:// www.nhc.gov.cn/mohwsbwstjxxzx/s8211/201610/9f109ff40e9346fca76dd82 cecf419ce.shtml. Accessed 26 Oct 2016.

13. Li A, Shi Y, Yang X, Wang Z. Effect of critical illness insurance on household catastrophic health expenditure: the latest evidence from the National Health Service Survey in China. Int J Environ Res Public Health. 2019;16(24): 5086. https://doi.org/10.3390/ijerph16245086.

14. Li X, Lu J, Hu S, et al. The primary health-care system in China. Lancet. 2017; 390(10112):2584-94.

15. Meng $Q, X u L$, Zhang $Y$, et al. Trends in access to health services and financial protection in China between 2003 and 2011: a cross-sectional study [published correction appears in lancet. 2012;380(9845):888. Lancet. 2012;379(9818):805-14.

16. Huisman M, Kunst AE, Mackenbach JP. Socioeconomic inequalities in morbidity among the elderly; a European overview. Soc Sci Med. 2003;57(5): 861-73. https://doi.org/10.1016/s0277-9536(02)00454-9.

17. Massamba VK, Talbot D, Milot A, et al. Assessment of the healthy worker survivor effect in the relationship between psychosocial work-related factors and hypertension. Occup Environ Med. 2019;76(6):414-21. https://doi.org/10 1136/oemed-2018-105460.

18. Zhai F, Wang H, Du S, et al. Prospective study on nutrition transition in China. Nutr Rev. 2009;67(Suppl 1):S56-61. https:/doi.org/10.1111/j.1753-4887.2009.00160.x.

19. Yin $M$, Augustin B, Fu Z, et al. Geographic distributions in hypertension diagnosis, measurement, prevalence, awareness, treatment and control rates among middle-aged and older adults in China. Sci Rep. 2016;6:37020. Published 2016 Nov 14. https://doi.org/10.1038/srep37020.

20. Wang Z, Chen Z, Zhang $L$, et al. Status of hypertension in China: results from the China hypertension survey, 2012-2015. Circulation. 2018;137(22): 2344-56. https://doi.org/10.1161/CIRCULATIONAHA.117.032380.

21. Hankivsky $\mathrm{O}$. Women's health, men's health, and gender and health: implications of intersectionality. Soc Sci Med. 2012;74(11):1712-20. https:// doi.org/10.1016/j.socscimed.2011.11.029.

22. Snow RC, Laski L, Mutumba M. Sexual and reproductive health: progress and outstanding needs. Glob Public Health. 2015;10(2):149-73. https://doi. org/10.1080/17441692.2014.986178.

23. Ruggieri A, Anticoli S, D'Ambrosio A, et al. The influence of sex and gender on immunity, infection and vaccination. Ann Ist Super Sanita. 2016;52(2): 198-204. https://doi.org/10.4415/ANN_16_02_11.

24. Wu C, Smit E, Xue QL, et al. Prevalence and correlates of frailty among community-dwelling Chinese older adults: the China health and retirement longitudinal study. J Gerontol A Biol Sci Med Sci. 2017;73(1):102-8. https:// doi.org/10.1093/gerona/glx098.

25. Blümel JE, Arteaga E. The risks of avoiding hormone replacement therapy during menopause. Rev Med Chil. 2017;145(6):760-4. https://doi.org/10. 4067/s0034-98872017000600760.

26. Jing S, Yin A, Shi L, Liu J. Whether new cooperative Mmedical schemes reduce the economic burden of chronic disease in rural China. PLoS One. 2013;8(1):e53062. https://doi.org/10.1371/journal.pone.0053062.

27. Sun Q, Liu X, Meng Q, et al. Evaluating the financial protection of patients with chronic disease by health insurance in rural China. Int J Equity Health. 2009;8:42. https://doi.org/10.1186/1475-9276-8-42.

28. Tian $D$, Sun $L$, Zhang $L$, et al. Large urban-rural disparity in the severity of two-week illness: updated results based on the first health service survey of Hunan Province, China. Int J Equity Health. 2016;15:37. https://doi.org/10. 1186/s12939-016-0330-z.

29. Cramer RJ, Ireland JL, Hartley V, et al. Coping, mental health, and subjective well-being among mental health staff working in secure forensic psychiatric settings: results from a workplace health assessment. Psychol Serv. 2019. https://doi.org/10.1037/ser0000354.

\section{Publisher's Note}

Springer Nature remains neutral with regard to jurisdictional claims in published maps and institutional affiliations. 